\title{
O que difere uma língua ergativa de uma língua nominativa?
}

What differentiates an ergative language from a nominative language?

\section{Fábio Bonfim Duarte ${ }^{1}$ Universidade Federal de Minas Gerais}

\section{Resumo}

Este artigo tem por objetivo mostrar as propriedades gramaticais que diferem as línguas ergativas das línguas nominativas. Assumese que o parâmetro que distingue os dois tipos de línguas está diretamente conectado com o fato de o Caso ergativo ser somente atribuído em línguas ergativas, nunca em línguas nominativas. Adicionalmente, discute-se que sistemas cindidos tendem a aparecer somente em línguas morfologicamente ergativas, mas não em línguas sintaticamente ergativas. Nesta perspectiva, sistemas de caso tripartidos são mais previsíveis em línguas morfologicamente ergativas. Por sua vez, línguas sintaticamente ergativas tendem a ser mais uniformes no sentido de que o Caso nominativo é, em geral, atribuído a sujeitos de intransitivos e a objetos de transitivos. Esta correlação explica a razão por que há uma tendência de os argumentos que carregam Caso absolutivo em línguas sintaticamente ergativas exibirem certos comportamentos sintáticos que, em geral, estão associados àqueles dos sujeitos em línguas acusativas.

\section{Palavras-chave}

Ergativo, Nominativo, Caso abstrato, Línguas indígenas, Minimalismo. 


\section{Abstract}

This paper aims to show the grammatical properties that distinguish ergative languages from nominative languages. It is assumed that the parameter that contrasts both types of languages has to do with the activation of the inherent ergative Case, which is assigned only in ergative languages. This means that this Case is never present in nominative languages. Additionally, it is argued that split systems tend to appear only in morphologically ergative languages as opposed to what happens in syntactically ergative languages, which do not exhibit splits. In line with this, tripartite case systems are predictable in morphological ergative languages. On the other hand, syntactically ergative languages tend to be more uniform in the sense that the nominative Case is usually assigned both to transitive objects and to intransitive subjects. This explains the reasons why there is a tendency in syntactically ergative languages for the absolutive arguments to exhibit a syntactic behavior commonly associated with the behavior of subject in accusative languages.

\section{Keywords}

Ergative, Nominative, Abstract case, Indigenous languages, Minimalism. 
$\mathrm{P}$ ara responder à pergunta que compõe o título do presente texto é preciso ter em conta quais são exatamente as propriedades morfossintáticas que diferem as línguas ergativas das línguas nominativas. Por essa razão, o objetivo principal deste trabalho é contribuir para uma compreensão mais acurada sobre o fenômeno da ergatividade. Para tal, utilizar-me-ei de conceitos advindos da linguística descritiva e da teoria gerativa. Com relação a esta última, retomarei desenvolvimentos recentes da Teoria de Caso, ${ }^{2}$ no intuito de compreender até que ponto os sistemas ergativos diferem dos sistemas nominativos encontrados, por exemplo, nas línguas indo-europeias. A análise se ancorará ainda em resultados que apurei a partir da pesquisa que venho desenvolvendo, tomando por base a análise comparativa de dados de línguas indígenas brasileiras. Uma das questôes centrais que estive avaliando no último período é se Caso ergativo corresponde mesmo a Caso inerente ou se, ao contrário, equivale a Caso estrutural. Outro objetivo tem sido testar se Caso absolutivo equivale a Caso nominativo ou a Caso acusativo. Para tanto, foram levados em consideração dados de dois conjuntos de línguas brasileiras. $\mathrm{O}$ primeiro conjunto inclui as línguas tenetehára e ka’apor, ambas pertencentes à família linguística tupi-guarani. O segundo conjunto compreende línguas do tronco linguístico macro-jê, como o apãniekra, o apinajé e o parkatejê, pertencentes à família linguística jê, e ao maxacali, pertencente à família linguística de mesmo nome.

Este texto está organizado em seis seçôes. A seção 1 retoma as propriedades gramaticais das línguas nominativas e sugere que essas línguas não exibem cisões de caso como as que ocorrem em línguas morfologicamente ergativas. Já a seção 2 discute as diferenças existentes entre línguas morfologicamente ergativas e as línguas sintaticamente ergativas. Na seção 3, mostro a existência de ergatividade em línguas do tronco linguístico macro-jê. A hipótese lançada é a de que o maxacali é uma língua ergativa ativa com um interessante sistema de Caso tripartido. Na seção 4, o objetivo é mostrar que o ka apor apresenta um sistema 
fluído e cindido no sistema de codificação dos argumentos nucleares. A seção 5 apresenta uma análise do sistema de caso e concordância do tenetehára, no intuito de demonstrar que esta língua exibe propriedades sintáticas híbridas, pois mistura características de línguas nominativas e de línguas ergativas. Por fim, a seção 6 apresenta as considerações finais.

\section{Línguas nominativas}

De maneira geral, podemos afirmar com certa segurança que as línguas nominativas exibem um sistema de Caso muito mais previsível e regular, quando comparadas com as línguas ergativas. Em condições não marcadas, pode-se assumir que uma língua nominativa apresenta um sistema de Caso cuja principal característica é o fato de o sujeito do verbo transitivo e o sujeito do verbo intransitivo receberem o mesmo Caso, mais precisamente o Caso nominativo, enquanto o objeto do verbo transitivo recebe o Caso acusativo. Essa é a situação, por exemplo, no japonês, em que o sujeito de verbos transitivos e de intransitivos recebe uniformemente a marca de Caso nominativo $=g a$, enquanto o objeto recebe a marca de Caso acusativo $=o$, conforme demonstram os dados a seguir:

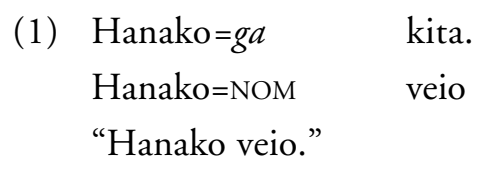
(2) Hanako $=g a \quad$ Taro $=0 \quad$ hihan-sita.
Hanako $=$ NOM Taro $=$ ACC criticar $-\mathrm{PASSADO}$
"Hanako criticou Taro."

Outra característica das línguas nominativas é o fato de não haver cisões na marcação de Caso dos argumentos nucleares, como as que ocorrem em línguas ergativas. Por essa razão, a literatura técnica não costuma considerar a existência de línguas nominativas cindidas. Aliado a isso, no âmbito da teoria de Caso, assume-se que o núcleo funcional Tense, doravante $\mathrm{T}^{\circ}$, é em geral responsável pela atribuição do Caso nominativo ao sujeito dos verbos transitivos e intransitivos em sentenças finitas, enquanto o núcleo $v^{0}$ atribui o Caso acusativo ao argumento interno em construçóes transitivas. Deixando de lado neste momento questóes de ordem linear, assumamos que a estrutura sintática abstrata abaixo corresponda 
à derivação sintática de uma sentença transitiva finita em qualquer língua nominativa.

(3) Atribuição dos Casos nominativo e acusativo em sentença transitiva

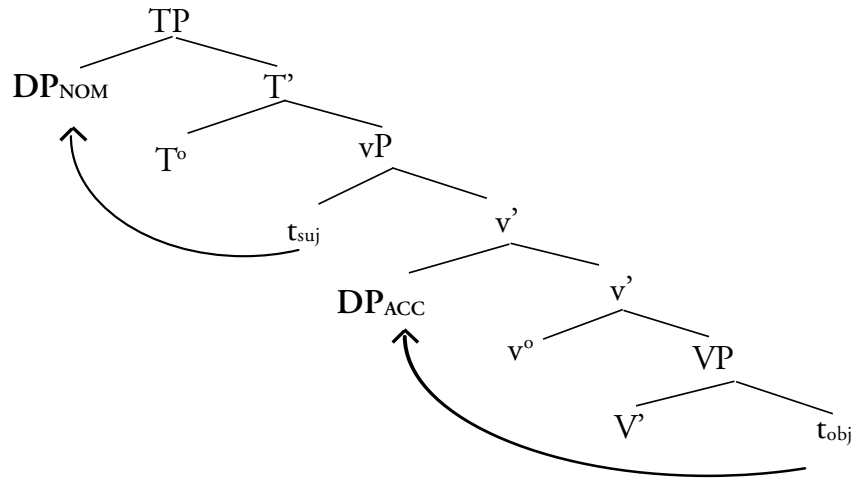

(4) Atribuição do Caso nominativo ao único argumento de verbos intransitivos

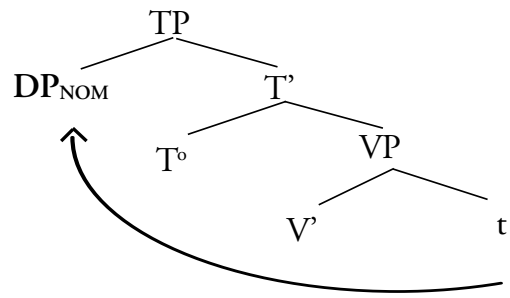

Em suma, podemos concluir que a principal característica de uma língua nominativa, do ponto de vista da teoria de Caso, é o fato de os sujeitos de verbos transitivos e intransitivos terem seu Caso atribuído pelo núcleo $\mathrm{T}^{\circ}$. Note-se que esse é o contexto de atribuição canônica de Caso. Todavia, pode ocorrer ainda uma situação em que o núcleo $T^{\circ}$ entra na derivação sem Caso estrutural a valorar, como ocorre, por exemplo, nas orações não finitas do inglês. Em tais contextos, o sujeito do verbo (transitivo ou intransitivo) precisará ter seu Caso valorado excepcionalmente por outro núcleo, de modo a não violar o filtro de Caso. ${ }^{3} \mathrm{Um}$ desses núcleos pode ser, por exemplo, o núcleo $v^{\circ}$ da oração matriz. Note-se que, em tais contextos, o Caso do sujeito corresponderá ao acusativo, e não ao nominativo, conforme ilustram os exemplos a seguir. 
(5a) We believed [Zeus to be omnipotent].

(5b) No one expected [Agamemnon to win].

Uma evidência a favor de que o Caso do sujeito da oração encaixada é realmente o acusativo pode ser obtida via pronominalização do sujeito. Note que os pronominais que emergem na posição de sujeito equivalem às formas acusativas e não às formas nominativas, conforme mostram os exemplos a seguir.

(6a) We [v believed [тр him to be omnipotent].

(6b) No one [v expected [тр him to win].

Note-se ainda que a razão por que o sujeito das sentenças acima vem com o Caso acusativo está diretamente conectada com as propriedades morfossintáticas do núcleo $T^{\circ}$ da oração encaixada. Mais precisamente, como esse núcleo não entra na derivação com Caso nominativo a valorar e como a oração é não finita, só restará ao DP sujeito da oração encaixada receber o Caso acusativo do núcleo $v^{\circ}$ da oração matriz.

\section{Línguas ergativas}

Sistemas ergativos diferem dos sistemas nominativos pelo fato de o sujeito do verbo transitivo receber, em geral, Caso ergativo, ao passo que o sujeito do verbo intransitivo e o objeto do verbo transitivo recebem Caso absolutivo, conforme mostram os exemplos da língua inuit a seguir.

(7) Jaani-up $\mathrm{C}_{\mathrm{C} 1}$ natsiq- $\varnothing_{\mathrm{C} 2}$ kapi-jaNa

Jaani-ERG foca-ABS apunhalar-TRANS

"Jaani apunhalou uma foca."

(8) inuk- $\varnothing_{\mathrm{C} 2}$ tikit-tuq

person-ABS chegou

"A pessoa chegou".

(9) ilinniaqtitsiji $\varnothing_{\mathrm{C} 2}$ uqaq-tuq

professor-ABS falou

"O professor falou." 
Outra diferença, bastante relatada pela literatura, consiste no fato de a ergatividade não constituir um fenômeno único e previsível, como parece ser a situação nos sistemas nominativos. Mais precisamente, a intuição é a de que ergatividade não é um processo sintático idêntico, mas possivelmente relacionase a um epifenômeno mais geral, com peculiaridades de língua para língua. ${ }^{4}$ Por exemplo, a ideia partilhada por vários estudiosos, como Dixon $(1979,1994)$, Laka (1993, 2000, 2006), Bobaljik (1993, 2006), Bittner e Hale (1996), Legate (2006, 2008), Woolford (1997, 2006), Aldridge (2004, 2008), dentre outros, é a de que o parâmetro que difere as línguas ergativas das línguas nominativas é o fato de o sujeito dos verbos transitivos, em geral os de ação, receberem um Caso especial, o qual a literatura técnica tem rotulado de ergativo. No âmbito da teoria de Caso, assume-se que esse Caso seja atribuído pelo núcleo $v$ ao argumento externo que é projetado na posição de Spec- $v \mathrm{P}$ de sentenças transitivas e inergativas, conforme indica a configuração sintática abaixo.

(10)

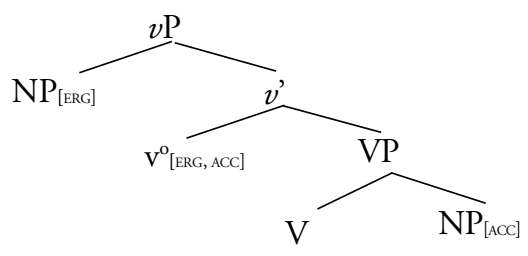

Nesse sentido, podemos notar que a principal diferença entre uma língua ergativa e uma língua nominativa advém do fato de que o Caso ergativo nunca está disponível em línguas nominativas. Outra hipótese que vem sendo assumida por muitos linguistas é a de que ergativo seja um subtipo de Caso inerente, pelo fato de este estar fortemente associado ao argumento externo que é selecionado tematicamente pelos verbos transitivos e inergativo no domínio do $v \mathrm{P}$. Em geral, esse argumento corresponde ao argumento que recebe o papel temático de agente. Isso fica particularmente evidenciado quando investigamos as línguas ergativas ativas. Nota-se que uma das principais propriedades dessas línguas é que o sujeito de verbos de ação, independentemente do fato de serem transitivos ou intransitivos (=inergativo), vem sempre marcado com o Caso ergativo. Esta é a situação que se verifica, por exemplo, no basco e no georgiano, conforme demonstram os exemplos a seguir. 


\section{Basco}

(11) Miren-ek atea ireki du.

Miren-ERG porta-NOM abrir AUX

"Miren abriu a porta"

(LEVIN, 1989, p. 20)

(12) Gizona-k kurritu du homem-ERG correr AUX

"O homem correu."

(LEVIN, 1983, p. 33)

\section{Georgiano}

(13)

$\begin{array}{lll}\text { Vano-m } & \text { gamozarda } & \text { dzma } \\ \text { Vano-ERG } & \text { levantar } & \text { irmão }\end{array}$

"Vano levantou o irmão"

(14) Bav Sv-ma itira

criança-ERG gritar

"A criança gritou"

Por sua vez, as línguas ergativas, embora tenham em comum o fato de o núcleo $v$ sempre atribuir inerentemente o Caso ergativo ao argumento externo, são comumente divididas em pelo menos dois subtipos, a saber:

(i) ergativas morfológicas;

(ii) ergativas sintáticas.

As próximas duas subseções, tem-se por objetivo detalhar as propriedades gramaticais de cada um desses tipos de ergatividade. Comecemos, então, com as línguas ergativas morfológicas.

\subsection{Ergatividade morfológica}

De maneira geral, línguas morfologicamente ergativas têm como principal característica a possibilidade de apresentarem cisão quanto ao Caso estrutural que é atribuído aos argumentos nucleares. Em geral, o que se nota é que essa cisão está diretamente conectada com os seguintes fatores: 
(i) o núcleo $v$ atribui Caso inerente (=ergativo) ao argumento externo e Caso estrutural ao objeto;

(ii) o núcleo $\mathrm{T}^{\mathrm{o}}$ atribui Caso nominativo ao sujeito de verbos intransitivos e ao sujeito de verbos transitivos antipassivizados.

O warlpiri é um bom exemplo desse tipo de língua, já que exibe cisão na atribuição de Caso dos argumentos nucleares, de maneira tal que emerge um sistema de Caso tripartido. Esse sistema surge do fato de o núcleo $v$, de sentenças transitivas, atribuir dois Casos: o ergativo, o qual é inerentemente atribuído ao argumento externo, e o absolutivo, o qual é atribuído estruturalmente ao objeto. Dessa maneira, a estrutura sintática em (16) corresponde à derivação da sentença transitiva (15).

(15)

$\begin{array}{lll}\text { Maliki-rli } & \text { ngarrka } & \text { yarlku-mu. } \\ \text { cachorro-ERG } & \text { homem-ABS } & \text { morder-PASSADO }\end{array}$

"Um cachorro mordeu um homem." (LEGATE, 2002, p. 130)

(16)

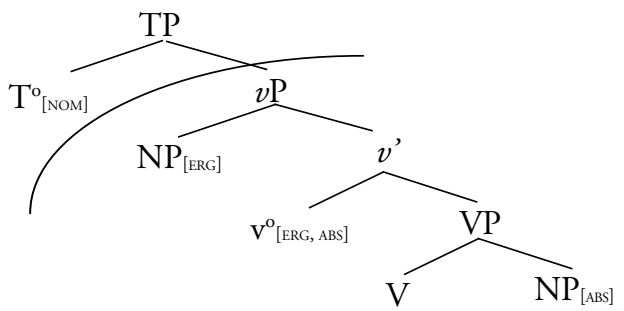

Aldridge (2008, p. 978) e Legate (2006, p. 152) ${ }^{5}$ observam que, na derivação acima, embora o núcleo T seja finito e carregue Caso nominativo, este Caso não será atribuído ao sujeito do verbo transitivo nem ao seu objeto, uma vez que os traços de Caso do sujeito e do objeto já são valorados pelo núcleo $v$, ainda na fase vP. Ou seja, em virtude do que estipula a restrição de impenetrabilidade de fase (PIC), ${ }^{6}$ nem o sujeito nem o objeto estão disponíveis para participar de operaçōes sintáticas na fase C/TP, já que o $v$ P é enviado a spellout e os constituintes sintáticos internos a esse $v \mathrm{P}$ ficam, portanto, impossibilitados de entrar em operações sintáticas com núcleos funcionais que estejam no domínio C/TP. Situação oposta emerge em orações intransitivas, já que o núcleo $v$ não pode atribuir Caso absolutivo. Nesse contexto, o sujeito de verbos inergativos, por exemplo, receberá Caso nominativo do núcleo T. Sendo assim, a sentença em (17) apresentará a derivação sintática proposta em (18). 
(17) parnka-ja-rna

correr-PASSADO-1SG

"Eu corri."

(Legate, 2006)

(18) Derivação de uma sentença intransitiva em warlpiri

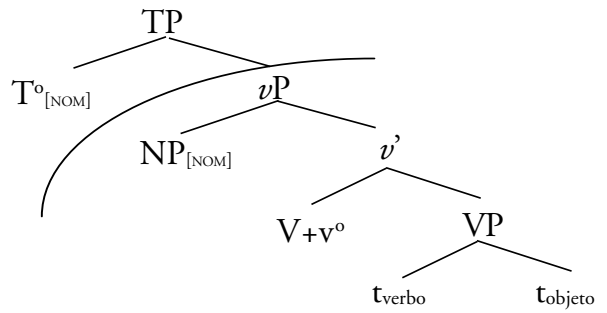

Tendo em conta a análise desenvolvida até aqui, nota-se que o warlpiri apresenta um sistema de Caso tripartido, conforme o resumo a seguir:

(i) o ergativo, atribuído inerentemente ao argumento externo pelo núcleo $\mathrm{v}^{\circ}$;

(ii) o absolutivo, atribuído estruturalmente ao objeto pelo núcleo $\mathrm{v}^{0}$;

(iii) o nominativo, atribuído pelo núcleo $\mathrm{T}^{\mathrm{o}}$ ao sujeito de intransitivos.

Adicionalmente, observa-se que o Caso absolutivo corresponde, no fim das contas, a Caso acusativo, já que ambos são atribuídos pelo núcleo $v^{\circ}$. Evidência em favor dessa assunção tem a ver com o fato de que o absolutivo pode ocorrer em orações infinitas do warlpiri, conforme ilustra o exemplo a seguir:

Warlpiri (LEGATE, 2002, p. 133)

(19) Ngarrka-patu-rlu ka-lu-jana puluku turnu-ma-ni homem-PAUC-ERG PRES.IMP-3P. gado juntar-NONPAST-SUBJ-3P.OBJ

[karnta-patu-rlu miyi purra-nja-puru] mulheres-PAUC-ERG comida.ABS cozinhar-INFIN-TEMPC

"Os homens estão juntando o gado enquanto as mulheres estão cozinhando."

Em síntese, o fato de o Caso absolutivo figurar em contextos em que T é não finito nos permite concluir que absolutivo realmente equivale a acusativo, já que a sua atribuição independe da finitude do núcleo T. ${ }^{7}$ Autores como Legate 
(2002, 2008) e Aldridge (2008) argumentam que não há Caso absolutivo distinto do acusativo em warlpiri. Esse fato levou-as postular que a ergatividade em línguas como o warlpiri corresponde, ao final das contas, a um fenômeno puramente morfológico, visto que o mecanismo de atribuição do Caso absolutivo e do Caso nominativo, nesta língua, não difere de maneira fundamental do das línguas nominativas. ${ }^{8}$

\subsection{Ergatividade sintática}

Línguas ergativas sintáticas diferem radicalmente das línguas ergativas morfológicas pelo fato de uma série de operaçōes sintáticas envolverem apenas o argumento que carrega o Caso absolutivo. A intuição é a de que esse argumento exibe propriedades gramaticais que são usualmente associadas ao sujeito em línguas nominativas. Isso fica particularmente sustentado pelo fato de que, em construções de controle obrigatório, apenas o DP com Caso absolutivo pode controlar a categoria vazia PRO que figura na posição de sujeito da sentença encaixada, conforme o exemplo a seguir:

\section{Dyirbal}

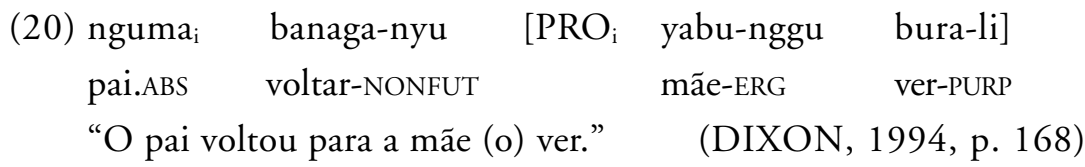

A mesma restrição também foi notada em contextos de orações coordenadas, já que o DP com Caso absolutivo necessariamente funciona como antecedente do sujeito da oração coordenada, conforme se observa pelo exemplo abaixo.

\section{Dyirbal}

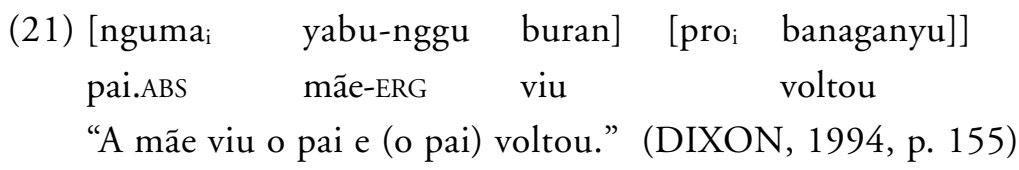

Restrição semelhante dá-se em contextos de relativização, visto que somente o argumento com Caso absolutivo pode figurar como o D/NP que encabeça a oração relativa, conforme se vê nos exemplos abaixo. 
(22) palan jukumpil ${ }_{\mathrm{i}}$ [ $\mathrm{e}_{\mathrm{i}}$ ngaja purangu $]$ nyinanyu a.ABS mulher.ABS 1s.NOM ver. REL.ABS sentar-NONFUT "A mulher que vejo está sentada." ～(LEVIN, 1983, p. 282)

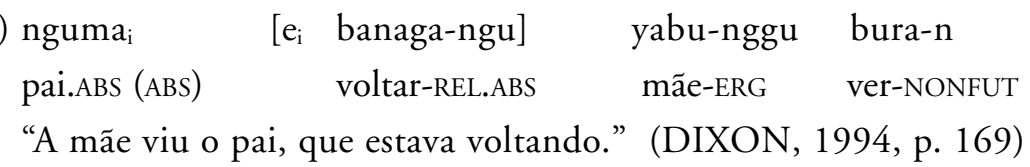

Note que o sujeito ergativo não pode ser relativizado nas orações acima. No entanto, esse argumento pode ser relativizado, desde que o verbo da oração encaixada seja antipassivizado por meio do sufixo -nga. Em geral, construçôes antipassivas possuem uma estrutura híbrida: semanticamente selecionam dois argumentos, um agente e um paciente / afetado / tema, e sintaticamente equivalem a uma construção intransitiva. Adicionalmente, quando da passagem $\mathrm{da}$ ativa para a antipassiva, ocorrem as seguintes mudanças gramaticais:

(i) o argumento externo muda seu Caso de ergativo para absolutivo;

(ii) o sujeito ergativo é promovido a sujeito da antipassiva;

(iii) o objeto é promovido a oblíquo.

Portanto, em contextos em que as operações sintáticas de (i) a (iii) são efetuadas, o argumento externo pode então ser relativizado, sendo extraído para a "cabeça" da construção relativa, conforme se vê pelo exemplo a seguir:

Dyirbal (DIXON, 1994, p. 170)

$\begin{array}{lllll}\text { (24) } \text { yabui }_{\mathrm{i}} & {\left[\begin{array}{llll}e_{\mathrm{i}} & \text { bural-nga-ngu } & \text { nguma-gu }\end{array}\right.} & \text { banaga-nyu } \\ \text { mãe.ABS } & & \text { ver-AP-REL.ABS } & \text { pai-DAT } & \text { voltar-NONFUT }\end{array}$

"A mãe, que viu o pai, estava voltando."

Outra propriedade comum às línguas sintaticamente ergativas é o fato de o núcleo $v^{o}$ não entrar, na derivação sintática, apto a atribuir Caso acusativo. Por essa razão, postula-se que $v^{\circ}$ possui um traço EPP saliente. Será, portanto, esse traço que explicará, por exemplo, o fato de o objeto poder ser sistematicamente movido para a margem esquerda de vP, na fase v-VP, posição a partir da qual poderá ser movido outra vez para posiçôes externas ao domínio v-VP, na fase $\mathrm{C}$-TP. Evidências de que o núcleo $v$ realmente não licencia Caso ao objeto advêm 
da observação empírica de que, em muitas línguas sintaticamente ergativas, o Caso absolutivo (=acusativo) não pode ocorrer em sentenças infinitivas. Outra propriedade surge do comportamento das construções antipassivas. Nessas construções, como o núcleo $v$ não carrega traço EPP saliente, nem pode atribuir Caso acusativo ao argumento interno, o objeto permanece in situ, recebendo, nesta posição, interpretação indefinida de escopo estrito. Consequentemente, um verbo transitivo terá de ser antes antipassivizado para que o argumento externo seja extraído para fora do vP, de modo a receber Caso nominativo do núcleo $\mathrm{T}$, na fase C-TP. Em suma, conclui-se que, em sentenças transitivas, antipassivas e intransitivas, o Caso absolutivo é sistematicamente atribuído pelo núcleo T, situação que nos permite propor que esse Caso equivale uniformemente ao nominativo nas línguas sintaticamente ergativas, já que $v$ não atribui Caso estrutural. Em tais configurações sintáticas, não haverá o surgimento de sistema de Caso cindido, já que o objeto e o sujeito de verbos intransitivos recebem Caso nominativo do núcleo T. Adicionalmente, o fato de o núcleo $v$ possuir traço EPP é a condição necessária para que o objeto possa ser atraído para a fase C-TP. Notese que o fato de o DP com Caso absolutivo (=nominativo) poder ser movido para fora do domínio v-VP é a condição sintática crucial para que uma determinada língua possa exibir ergatividade sintática. Isso explica a razão por que o argumento com o Caso absolutivo pode ser analisado, ao mesmo tempo, como objeto na estrutura argumental e sujeito na estrutura gramatical em línguas com ergatividade sintática. Em suma, podemos concluir que o traço EPP de $v$ e a possibilidade de extração do objeto para fora do $v \mathrm{P}$ constituem, assim, as duas peculiaridades principais que distinguem línguas sintaticamente ergativas de línguas morfologicamente ergativas. ${ }^{9}$ Dessa maneira, a estrutura abstrata de uma sentença transitiva em línguas sintaticamente ergativas deve ter o seguinte formato:

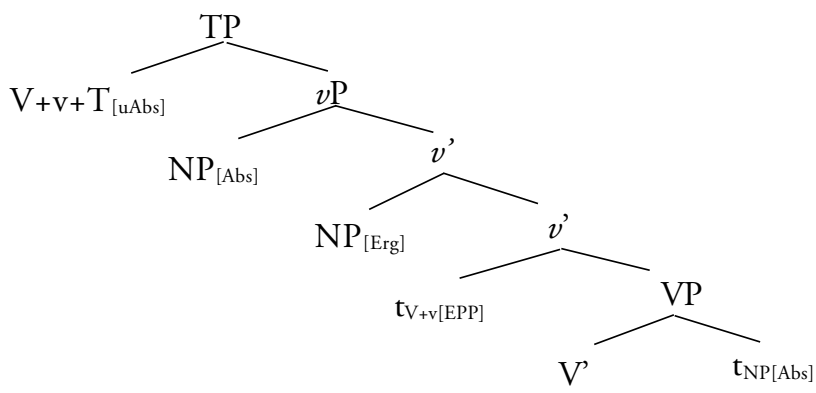


Consoante Aldridge (2008, p. 286), a proposta acima nos permite explicar a razão por que o DP com Caso absolutivo pode figurar externo a dois $v$ Ps coordenados. Dessa maneira, na derivação sintática do exemplo abaixo, a hipótese assumida por Aldridge é a de que o objeto primeiro é extraído para a margem esquerda do $v \mathrm{P}$, de modo a satisfazer o traço de margem de $v \mathrm{P} \mathrm{e}$, em seguida, é movido para a posição de Spec-TP, posição sintática na qual checa o seu Caso nominativo e valora o traço EPP de T.

\section{Dyirbal}

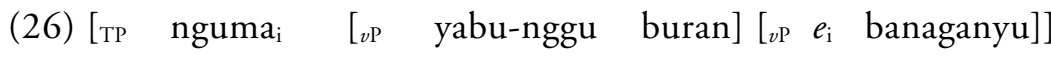
pai.ABS mãe-ERG viu voltou

"A mãe viu o pai e (o pai) voltou." (DIXON, 1994, p. 155)

As próximas seçôes têm o objetivo de apresentar os resultados da pesquisa que venho realizando, tomando por base as línguas indígenas brasileiras, no intuito de mostrar até que ponto essas línguas corroboram ou não as diferenças gramaticais apontadas acima entre línguas ergativas, de um lado, e línguas nominativas, de outro.

\section{Ergatividade em línguas do tronco linguístico Macro-Jê}

Em relação à ergatividade nas línguas do tronco linguístico macro-jê, uma importante descoberta que alcançamos na pesquisa recente foi a de que a língua maxacali comporta-se como uma língua ergativa ativa. ${ }^{10}$ Uma das evidências a favor dessa hipótese refere-se ao fato de a posposição te, que marca o Caso ergativo nessas línguas, poder figurar sistematicamente junto a sujeitos de verbos de ação. No caso do maxacali, a posposição te tem seu uso estendido inclusive a verbos inergativos, o que nos permitiu incluí-la no rol da tipologia de línguas ergativas ativas, conforme ilustram os dados os seguir:

\section{transitivos de ação}

$\begin{array}{llll}\text { kakxop } & \text { te } & \text { kuxxamuk } & \text { paha } \\ {\left[\text { kak' } t \text { orp }^{\top} \text { tæ } P\right.} & \text { kijtfa'buk' } & \text { pa'ha?] } \\ \text { menino } & \text { erg } & \text { lambari } & \text { pegar } \\ \text { "O menino pegou lambari." } & \text { (CAMPOS, 2007, p.39) }\end{array}$




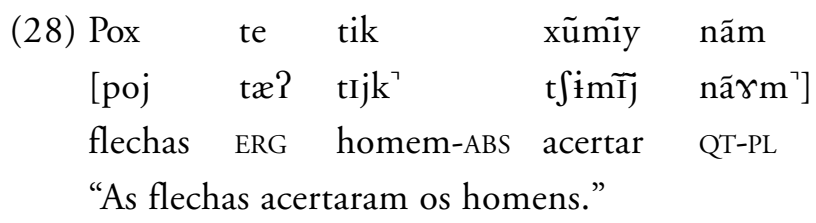

\section{intransitivos de ação}

(29) Kakxop te tatxok

[kak't $\left.\int u r p\right\urcorner$ tæ? ta3t't $\int$ owk]

menino ERG banhar

"O menino tomou banho."

(30) Yoãm te hãmyãg

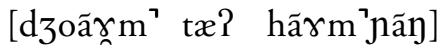

João ERG dançar

"O João dançou."

(CAMPOS, 2008, p. 72-73)

Já em apãniekra e parkatejê, encontramos um padrão ergativo muito similar ao do maxacali, visto que há biunivocidade entre a realização dos Casos ergativo e a atribuição do papel- $\theta$ [+AGENTE]. Tal correlação fica particularmente evidenciada pelo fato de tanto o apinajé quanto o parkatejê também disponibilizarem posposição ergativa homônima ao do maxacali para marcar o Caso ergativo em predicados transitivos, conforme mostram os exemplos a seguir:

\section{Apãniekra}

$\begin{array}{ccl}\text { (31) i-te } & \text { a } & \text { j-itep } \\ \text { 1-ERG } & 2 & \text { REL cortar } \\ \text { "eu te cortei" } & \end{array}$

(ALVES, 2004, p.118)

\section{Parkatejê}

(32) i-te

i-kra

pan

eu-ERG

1-filho

carregar+PASS

"Eu carreguei meu filho"

(FERREIRA, 2001, p.159) 
Os dados das línguas indígenas acima oferecem, portanto, de sustentação adicional para a hipótese de que realmente o parâmetro que distingue uma língua ergativa de uma língua nominativa é o fato de o Caso ergativo estar intimamente relacionado ao sujeito temático de verbos de ação. Tal correlação tem servido de esteio para a testagem da hipótese de que a valoração do Caso ergativo tem direta conexão com a atribuição do papel- $\theta$ [AGENTE] aos argumentos externos de verbos transitivos nas línguas indígenas pertencentes às famílias Jê e maxacali (cf. DUARTE, 2009 e DUARTE; BARCELOS-SILVA, 2010). Essa hipótese traz, por sua vez, reforço adicional para as teorias desenvolvidas por Legate (2002, 2008), Woolford (2006), Aldridge (2004, 2008), segundo as quais o Caso ergativo é atribuído inerentemente pelo núcleo $v$ em línguas ergativas. ${ }^{11}$

Outra conclusão a que cheguei é a de que o Caso absolutivo equivale a acusativo em maxacali, o que sugere que esta língua opera com um sistema tripartido semelhantemente ao que ocorre no warlpiri. Essa hipótese se sustenta nas construçôes em que a ordem muda de SOV para OSV. O curioso é que, nessas construçôes, o verbo apresenta concordância de pessoa e número com o objeto. Todavia, tal concordância não se observa nas orações ativas em que a ordem predominante é SOV. Com base nesses fatos, a hipótese de que o objeto tem seu traço de Caso alterado de acusativo para nominativo nas construções OVS ganha reforço adicional. Comparem-se os exemplos a seguir.

\section{voz ativa}
(33) Tikmû'ûn
te
kuxakuk
kix
[tijk'mũ?
kut $\left.\int a k u k k^{\prime} \quad \mathrm{krj}\right]$
maxakali
ERG
capivara.ABS
matar.PL

"Os maxakali mataram as capivaras."

\section{voz passiva}
(34) Kuxakuk
u-kix
tikmũũnte
[kut $\int a k u k$ '
ur-kij
tijk'mữ? ữ
capivara-ABS
3sg.-matar.PL
maxakali-ERG
"As capivaras foram mortas pelos maxakali." 
voz ativa

$\begin{array}{llll}\text { (35) Kakxop } & \text { te } & \text { okoa } & \text { kôyõy } \\ {\left[\text { kak`t } \int u r p\right\urcorner \text { tæ? }} & \text { okua } & \text { kujũ̃jn }] \\ \text { menino } & \text { ERG } & \text { copo-ABS } & \text { quebrar } \\ \text { "O menino quebrou o copo" } & \end{array}$

voz passiva

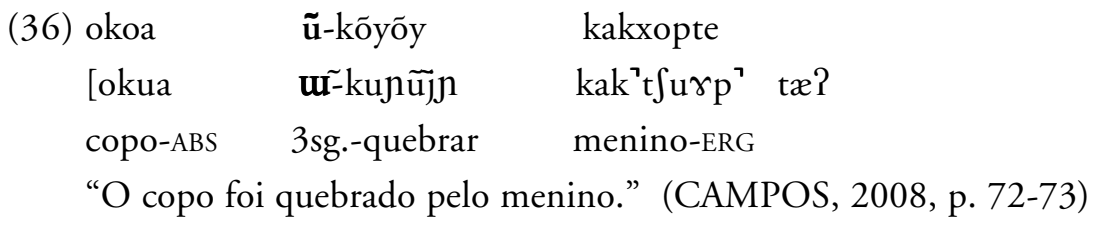

Nas construções acima, o argumento externo preserva o Caso ergativo, visto que o Caso não é alterado quando ocorre a mudança de ordem sintática de SOV para OSV, como muito frequentemente ocorre na transformação passiva em línguas nominativas. Tal fato mostra claramente que o maxacali exibe uma sintaxe distinta quando comparado com línguas nominativas, visto que nestas últimas o argumento externo costuma ser promovido a oblíquo na voz passiva, situação que, claramente, não se verifica em maxacali. Uma possível razão para explicar o padrão acima pode ser encontrada a partir da suposição de que o argumento externo, como já está marcado com a posposição ergativa, não sofrerá nenhuma promoção sintática em virtude de seu Caso já ter sido valorado inerentemente no domínio vP. Outro fato que chama a atenção nos dados acima é que, quando o objeto se move para a posição inicial, o verbo transitivo toma o prefixo $\tilde{\boldsymbol{u}}$-, o mesmo que também figura para marcar sujeito de verbos inacusativos. Tal fato mostra que os Casos do objeto e do sujeito de verbos intransitivos são atribuídos pelo mesmo núcleo. Comparem-se os dados a seguir.

(37) mĩkax

ũ- yãy- xaa

[mikaj

u - jãjn t $\left.\int a ? a ?\right]$

pedra

3SG REFL RACHAR

"A pedra rachou."

(CAMPOS, 2008a, p. 4) 
(38)

$\begin{array}{lll}\text { Ãyuhuk } & \text { kakxop } & \tilde{\mathbf{u}} \text {-top } \\ \text { [ãdzuhuk' } & \text { kak’t } \int \mathrm{urp} & \tilde{\boldsymbol{u}} \text {-torp?] } \\ \text { não índio } & \text { menino-ABS } & \text { 3sG-ser/estar gordo } \\ \text { "O menino não índio é gordo." } & \text { (CAMPOS, 2008, p. 5) }\end{array}$

Uma análise plausível é assumirmos que a ocorrência do prefixo de terceira pessoa $\tilde{\mathbf{u}}$-, nas estruturas inacusativas e passivas do maxacali, reflete o movimento do argumento interno de sua posição temática para a posição de Spec-TP. Isso, por sua vez, sinaliza que esse movimento é motivado para que esse argumento tenha seu Caso valorado pelo núcleo $\mathrm{T}^{\circ}$. Se essa proposta for mesmo confirmada, ficamos em condiçôes de assumir que o maxacali opera com um sistema tripartido. Evidentemente, tais hipóteses terão de ser mais bem exploradas na próxima etapa da pesquisa.

\section{Do sistema de Caso cindido em ka'apor}

O principal resultado que apurei até o momento sobre o sistema de Caso em ka’apor refere-se ao fato de essa língua apresentar uma cisão (Split-S System) quanto à codificação gramatical do sujeito dos verbos intransitivos. Essa marcação dá-se essencialmente por meio da ocorrência da partícula enclítica $=k e$, cuja função principal é denotar semântica de afetação. De maneira geral, observa-se que essa partícula marca argumentos internos de verbos transitivos e sujeitos de verbos inacusativos, conforme mostram os dados a seguir:

(39) ihe

$$
\begin{array}{lll}
\text { ihẽ } & \text { narãj=ke } & \text { a-pirok } \\
\text { eu } & \text { laranja=AFET } & \text { 1sG-descascar }
\end{array}
$$

"Eu descasquei a laranja."

(40)

$\begin{array}{llll}\text { a'e } & \text { tatu=ke } & \text { u-'u } & \text { ta } \\ \text { ele } & \text { tatu=AFET } & \text { 3-comer } & \text { vOL }\end{array}$

"Ele vai comer o tatu."

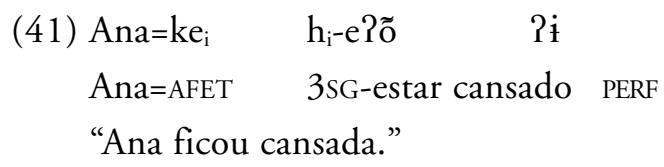




$$
\begin{array}{ll}
\text { (42) } \text { ihẽ }=\text { ke } & \text { a-'ar } \\
\text { eu=AFET } & \text { 1sG-cair } \\
\text { "eu caí." } &
\end{array}
$$

Tomando por base as ocorrências acima, a hipótese que tenho assumido é a de que $=k e$ serve como importante diagnóstico sintático-semântico para identificarmos quando determinado argumento é semanticamente afetado ou não pelo evento / estado denotado pela predicação principal. Adicionalmente, a distribuição morfossintática de $=k e$ demonstra que sua ocorrência sinaliza a existência de um interessante alinhamento sintático-semântico entre o DP sujeito de verbos intransitivos (descritivos e inacusativos) e o DP objeto. Esse tipo de alinhamento lembra muito o sistema que Dixon $(1979,1994)$ denomina de ergatividade cindida (splitergativity). De acordo com o que propõe Dixon (1979, 1994), ${ }^{13}$ em muitas línguas com ergatividade cindida, a tendência é a de que os argumentos que recebem o Caso absolutivo tendam a não vir marcados com Caso morfológico. Todavia, os dados do ka'apor contradizem essa predição, uma vez que os argumentos com Caso absolutivo são sim marcados na morfossintaxe, enquanto os argumentos com papel-q de agente prototípico não recebem qualquer marca. Note que essa observação é sustentada pelos dados abaixo:

(43)

$\begin{array}{lll}\text { arauxu } & \varnothing \text {-ahem } & \text { uhu } \\ \text { Araújo } & \text { 3sG-gritar } & \text { muito } \\ \text { "Araújo gritou muito." } & \end{array}$

(44) Purutu

$\varnothing$-ahem

Purutu 3SG-gritar

"Purutu gritou." [por vontade própria]

(45) Maíra $\varnothing$-wata

Maíra 3-caminhar

"Maíra caminhou." [por vontade própria]

(46) ihẽ

$$
\text { narãj=ke }
$$
a-pirok

eu

$$
\text { laranja }=\mathrm{AFET}
$$$$
\text { 1SG-descascar }
$$

"Eu descasquei a laranja." 
Em suma, a hipótese que venho propondo é a de que o ka'apor apresenta uma cisão quanto ao Caso que o sujeito do verbo intransitivo recebe. Tal situação gramatical me permitiu propor, por exemplo, que os verbos intransitivos podem ser subdivididos em pelo menos duas classes distintas de verbos: aqueles que selecionam um agente prototípico e os que selecionam um argumento afetado, conforme mostram as configurações sintáticas abaixo.

(47) Inergativos

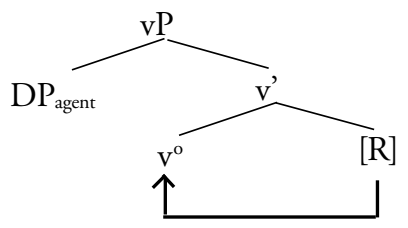

(48) Inacusativo

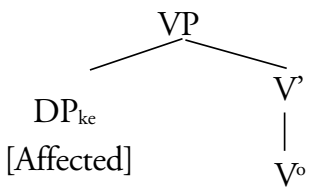

Contudo, além de marcar sujeitos de inacusativos e objetos diretos de verbos transitivos, foi ainda possível apurar contextos nos quais $=k e$ pode, sim, marcar sujeitos de verbos agentivos. Comparem-se os contrastes entre os exemplos (a) e (b) a seguir:

(49a)
Purutu=ke
$\varnothing$-ahem
Purutu=AFET
3SG-gritar
"Purutu gritou." [por ser afetado]

(49b) Purutu

$\varnothing$-ahem

Purutu

3SG-shout

"Purutu gritou." [por vontade própria]

(50a) Maíra =ke $\varnothing$-wata

Maíra=AFET 3-walk

"Maíra caminhou." [com esforço] 
(50b) Maíra $\quad \varnothing$-wata

Maíra 3-caminhar

"Maíra caminhou." [por vontade própria]

(51a) a'e ke u-'u ta pypyhu ke ti ele AFET 3sG-eat VOL coruja AFET REP "Ele vai comer a coruja."

(51b) a'e tatu=ke u-'u ta he tatu=AFET 3-comer VOL

"Ele vai comer tatu."

Notem que, nos contextos em (a) acima, o sujeito não corresponde exatamente a um agente prototípico, mas, sim, a um argumento cujo papel temático é de natureza híbrida. Em outras palavras, esse sujeito, embora seja argumento de um verbo de atividade, exibe alto grau de afetação. Tal fato me levou a postular que esses argumentos correspondem ao que Saksena (1980) descreve como um agente afetado em línguas como o Hindi. ${ }^{14}$ Ademais, observe -se que a presença de $=k e$ serve para codificar contrastes como volição / propósito versus necessidade / obrigação. Isso fica particularmente assentado pelo fato de, nos exemplos em (a), o significado envolver a realização de uma ação com afetação / sofrimento, por parte do agente. Por essa razão, uma terceira conclusão a que cheguei, no decorrer da pesquisa, é a de que, além do sistema cindido, o ka’apor exibe também um sistema fluido na codificação dos sujeitos dos verbos inergativos e transitivos. ${ }^{15}$ Dessa maneira, qualquer sujeito de inergativos e transitivos pode, em tese, vir marcado por meio de $=k e$, de sorte que verbos de ação (transitivos e inergativos) podem de fato selecionar um agente afetado ou um agente prototípico. Uma ou outra opção dependerá, naturalmente, de o sujeito ser afetado ou não no evento. Tal conclusão aponta, portanto, para o fato de que o ka'apor pode ser classificado tipologicamente como mais uma língua da América do Sul que exibe um sistema fluido. De acordo com Dixon (1994, p. 81), apenas o baniwa do içana havia sido até então classificado como sendo uma língua que apresenta sistema fluido na região amazônica. ${ }^{16}$ No entanto, tendo em vista os dados que acabo de arrolar, além do baniwa, proponho acrescentar a língua ka’apor ao inventário tipológico das línguas da América do Sul que apresentam sistema fluido na codificação de sujeitos agentivos de verbos transitivos e inergativos. 
Uma questão que ficou em aberto para ser investigada em detalhe na pesquisa futura é saber qual é exatamente o estatuto teórico da partícula $=k e$. Por essa razão, o que precisamos determinar com mais precisão éo estatuto gramatical da partícula $=k e$, no intuito de responder à seguinte pergunta: seria a partícula $=k e$ uma instanciação morfossintática de Caso estrutural ou de Caso inerente? Para responder a essa pergunta, partirei da proposta de Woolford (2006), segundo a qual a teoria de Caso é composta de dois Casos abstratos: o Caso estrutural e o Caso não estrutural. A principal diferença entre os tipos de Caso é que Caso estrutural é sempre dissociado de papel temático, de sorte que é atribuído no domínio funcional da sentença, e não no âmbito da estrutura argumental. Essa teoria pressupóe ainda que Caso estrutural pode estar associado a mais de um papel temático, fato que o distingue radicalmente de Caso não estrutural. Este último, por sua vez, está diretamente conectado a determinadas posiçōes temáticas na sentença. Na literatura recente (URA, 2001; WOOLFORD, 1997, 2006; LEGATE, 2006; LAKA, 2006), assume-se que Caso não estrutural compreende dois tipos de Caso: o Caso lexical e o Caso inerente. $\mathrm{O}$ primeiro é idiossincrático e imprevisível, enquanto o Caso inerente é muito mais regular e previsível. Consoante a essa proposta, Caso inerente é geralmente conectado com as posiçôes temáticas de agente e de alvo / experienciador. Nessa linha de raciocínio, o ergativo equivale ao Caso inerente associado aos argumentos que recebem papel temático de agente, enquanto o dativo corresponde ao Caso inerente associado aos argumentos que exibem o papel-q de alvo / experienciador, conforme ilustram os dados a seguir.

(52)

$\begin{array}{llll}\text { Miren-ek } & \text { atea } & \text { ireki } & \text { du } \\ \text { Miren-ERG } & \text { porta-NOM } & \text { abrir } & \text { AUX } \\ \text { "Miren abru a porta" } & & & \text { (LEVI }\end{array}$

"Miren abriu a porta."

(LEVIN, 1989, p. 20)

(53)

$\begin{array}{lll}\text { Taroo-ni } & \text { eigo-ga } & \text { hanaseru. } \\ \text { Taro-DAT } & \text { inglês-NOM } & \text { falar-pode }\end{array}$

"Taro pode falar inglês."

(SHIBATANI, 1977, p. 806)

(54) Dann hat Hans der Erna einen $\mathrm{Ku} \beta$ gegeben

então tem Hans a Erna-DAT um beijo-ACC dado

"Então Hans deu um beijo em Erna." (CZEPLUCH, 1988, p.92)

Por sua vez, nos exemplos abaixo, o dativo em (55) e o acusativo em (56) são exemplos de Caso idiossincrático em Islandês. No âmbito da teoria de Caso, 
a intuição é a de que esses Casos são licenciados pelas entradas lexicais dos verbos correspondentes a "virar" e "desviar".

(55) Bátnum barco-DAT "O barco virou." hvolfdi

virar

(LEVIN; SIMPSON 1981, 1b)

(56) Bátinn

rak á land. barco-ACC desviou para margem.

"O barco desviou (foi levado pela corrente) para a margem ."

(JÓNSSON, 2003, 66a)

Outra importante assunção é a de que o Caso inerente nunca ocorre em argumentos internos, mas somente em argumentos externos. A consequência dessa proposta é a de que argumentos internos, os quais, em geral, carregam papel temático de tema / afetado / paciente, nunca recebem Caso inerente. O oposto será também verdadeiro, ou seja, argumentos externos que recebem papel temático de agente / experienciador não podem receber Caso lexical, pois, em geral, só podem receber Caso ergativo e dativo, respectivamente. ${ }^{17}$ Em síntese, o que essa teoria prevê é que argumentos internos com Caso inerente e argumentos externos com Caso lexical não serão licenciados em nenhuma língua. Tendo em conta o que a teoria de Caso acima prediz e o fato de argumentos externos e internos poderem vir marcados com =ke na língua ka’apor, a hipótese que assumirei é que essa partícula reflete, no fim das contas, a realização de um subtipo de Caso abstrato. Adicionalmente, tendo em conta que há sim certa associação entre a ocorrência de $=k e$. e a semântica de afetação, admitirei que o Caso que essa partícula instancia é um subtipo de Caso não estrutural associado a esse traço semântico. A pesquisa futura deverá determinar com mais exatidão qual tipo de Caso inerente a partícula $=k e$ instancia.

\section{Sobre o sistema de Caso cindido em tenetehára}

Na língua tenetehára, sintagmas nominais não exibem morfologia casual. Contudo, existe um rico sistema de concordância no verbo que compensa a falta de Caso no sujeito e no objeto. Por essa razão, a língua disponibiliza duas séries distintas de marcadores de pessoa: os prefixos nominativos e os clíticos 
absolutivos / acusativos. Nota-se ainda que há uma interessante distribuição complementar entre as duas séries, que pode ser descrita da seguinte maneira: (a) prefixos nominativos não estabelecem concordância com o objeto e (b) os clíticos absolutivos / acusativos não codificam o sujeito de verbos transitivos. $\mathrm{O}$ paradigma completo com as duas séries é apresentado nos quadros a seguir.

(57)

\begin{tabular}{|c|c|c|}
\hline \multicolumn{3}{|c|}{ Prefixos nominativos } \\
\hline Pessoa & Singular & Plural \\
\hline 1 & $\mathrm{a}-$ & $x i-/ z a-{ }_{\text {inclusive }}$ \\
uru- & pexclusive \\
2 & $(e) r e$ & pe- \\
3 & $u-\sim o-\sim w-$ & - \\
\hline
\end{tabular}

(58)

\begin{tabular}{|l|l|l|}
\hline \multicolumn{3}{|c|}{ Clíticos acusativos / absolutivos } \\
\hline Pessoa & Singular & Plural \\
\hline 1 & he- & zane- $_{\text {inclusive }}$ \\
& & ure $_{\text {exclusive }}$ \\
2 & ne- & pe- \\
3 & i- & - \\
& h- & \\
\hline
\end{tabular}

A hipótese teórica que venho explorando em meus trabalhos mais recentes é a de que o sistema de Caso cindido da língua tenetehára permite uma variação paramétrica não prevista pela teoria do Parâmetro Obrigatório de Caso (Obligatory Case Parameter, doravante OCP). Esse parâmetro foi proposto por Laka (1993, 2000) e Bobaljik (1993) e prevê que a atribuição de Caso estrutural ao único argumento do verbo intransitivo dependerá de qual categoria funcional estiver ativa nas línguas. Por exemplo, a intuição é a de que, numa língua nominativa, o único argumento do verbo monoargumental recebe Caso nominativo do núcleo $T$, enquanto, em uma língua ergativa, o único argumento do verbo monoargumental recebe Caso absolutivo / acusativo do núcleo $v$. Um aspecto relevante dessa teoria diz respeito ao fato de o parâmetro de atribuição 
de Caso não se aplicar aos predicados transitivos, mas somente aos predicados intransitivos, visto que ao sujeito de verbos intransitivos poderá ser atribuído o Caso nominativo ou o Caso absolutivo, de modo que a ocorrência de um ou de outro dependerá, portanto, das escolhas paramétricas de cada língua. Levandose em consideração que o parâmetro é sempre de natureza binária e que poderá ativar o Caso nominativo ou o Caso acusativo nos predicados monoargumentais, Laka (1993, 2000) e Bobaljik (1993) propuseram que o acionamento do Caso estrutural ao sujeito $(\mathrm{S})$ pode resultar nas seguintes possibilidades tipológicas:

\section{Parâmetro obrigatório de Caso}

\section{Línguas Nominativas}

(59) Se $\mathrm{C} 1_{\text {nominativo }}$ estiver ativo
(a) $\mathrm{V}_{\text {transitivo }}$
$\left(\mathrm{C} 1_{\text {nom }}, \mathrm{C} 2_{\text {acc }}\right)$
(b) $V_{\text {intransitivo }}$
$\left(\mathrm{C} 1_{\text {nom }}\right)$

\section{LÍNGUAS ERGATIVAS}

(60) Se C2 $2_{\text {absolutivo }}$ estiver ativo
(a) $\mathrm{V}_{\text {transitivo }}$
$\left(\mathrm{C} 1_{\text {erg }}, \mathrm{C} 2_{\text {abs }}\right)$
(b) $\mathrm{V}_{\text {intransitivo }}$
$\left(\mathrm{C} 2_{\mathrm{abs}}\right)$

No sistema acima, C1 é o Caso atribuído pelo núcleo T e C2 é o Caso atribuído pelo núcleo v, conforme mostra a configuração sintática a seguir:

(61)

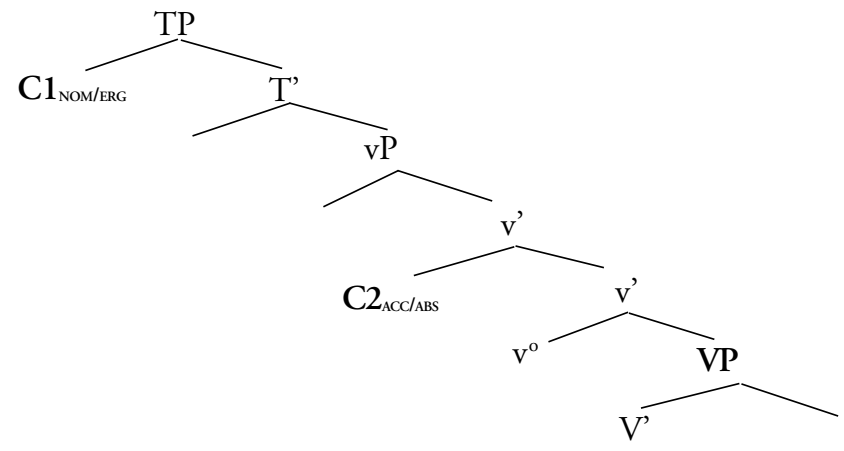


Tendo em conta o que estipula o OCP em (59) e (60) e a estrutura sintática em (61), a questão que se coloca para análise é como dar conta do fato de o Caso do sujeito do verbo monoargumental realizar-se ora como nominativo, ora como absolutivo / acusativo, situação que indica que o OCP é uma generalização que não dá conta de explicar os dados do tenetehára. Em outras palavras, essa língua permite uma variação não prevista pelo $\mathrm{OCP}$, uma vez que o Caso estrutural do sujeito dos verbos intransitivos é dependente dos núcleos $v \mathrm{e}$ T. Mais precisamente, o que se observa é que o Caso dos sujeitos dos verbos monoargumentais pode realizar-se ora como o nominativo, ora como o acusativo. ${ }^{18}$ Tal alternância fica particularmente instanciada pelo fato de o sujeito poder vir marcado pelo prefixo nominativo, conforme mostram os exemplos em (a), ou pelo clítico acusativo / absolutivo, conforme os exemplos em (b).

(62a) o-ho kwez

3SG-ir IPASS

"Ele foi embora."

$\begin{array}{ll}\text { (62b) i-ho-re } & \text { a- ha } \\ \text { 3sG-ir-depois } & \text { 1sG-ir }\end{array}$

"Depois que ele foi embora, eu saí."

(63a) àmàn u-kyr

chuva 3SG-chover

“Chove." (lit. "A chuva chove").

(63b) àmàn i-kyr mehe (...)

chuva 3sG-chover COMP

"Quando chove, ..."

(64a) u-hy u-ze'eg ne-we

dele-mãe 3sG-falar tu-com

"A mãe dele falou contigo."

(64b) $\mathrm{u}_{\mathrm{i}}$-wàpytymawok $\mathrm{w}_{\mathrm{i}}$-azuru pro $\mathrm{i}_{\mathrm{i}} \mathrm{i}_{\mathrm{i}}$-ze'eg pà

3sG-abrir dele-boca pro 3sG-falar COMP

"Ele abriu a boca (dele) para falar." 
(65a) a-ker kwej

1-dormir PERF

"Eu já dormi."

(65b) he- $\varnothing$-ker pà

I-ABS-dormir COMP

"Enquanto eu estava dormindo ..."

Uma maneira de interpretarmos teoricamente a distribuição dos marcadores de pessoa nas construções acima é postularmos a seguinte generalização:

(66) Os prefixos nominativos são engatilhados sempre que T entrar na derivação sintática a atribuir Caso nominativo, enquanto os clíticos acusativos são ativados nos contextos em que o núcleo v pode atribuir Caso acusativo / absolutivo.

A consequência imediata da generalização acima é que teremos de assumir que sujeitos de intransitivos e sujeitos de transitivos dependerão do núcleo T para receber Caso nominativo em oraçōes raízes, conforme a estrutura abstrata a seguir:

(67) Atribuição de Caso em orações intransitivas

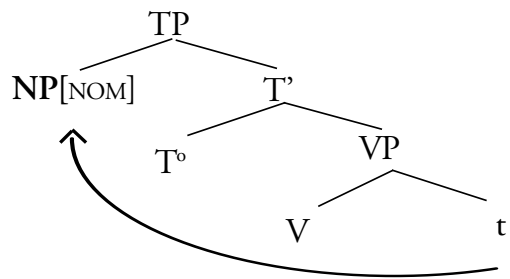

Evidência a favor da estrutura acima advém da observação empírica de que, em oraçóes raízes, sujeitos de transitivos e sujeitos de intransitivos não são referidos no verbo por meio dos clíticos acusativos, mas somente pelos prefixos nominativos, conforme indica a agramaticalidade das sentenças em (b) abaixo:

$\begin{aligned} \text { (68a) } & \text { a-(a)ro-rəm } \\ \text { eu-esperar-FUT homem } & \text { awa } \\ & \text { "Eu vou esperar pelo homem." }\end{aligned}$ 


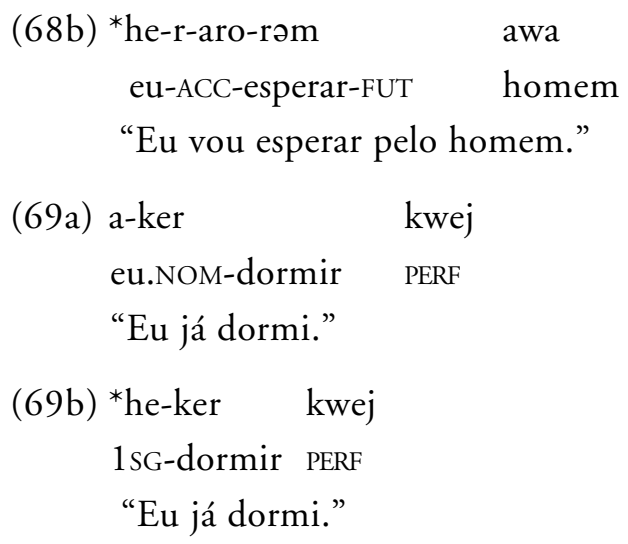

Em resumo, o paradigma acima claramente indica que orações raízes exibem um sistema nominativo acusativo, já que o sujeito de transitivos e o sujeito de intransitivos recebem o mesmo Caso estrutural. Outra consequência da generalização em (66) se refere ao núcleo T não atribuir Caso ao sujeito de intransitivos em orações subordinadas. Nota-se que, em tais contextos, os traços de Caso dos sujeitos intransitivos são atribuídos pelo núcleo $v$, e não pelo núcleo T. Se este último núcleo pudesse atribuir Caso, os prefixos nominativos deveriam poder ocorrer na raiz verbal em tais oraçôes, situação que evidentemente não é possível, conforme a agramaticalidade das sentenças a seguir:
(70) *he- $\varnothing$-hy
hie pe a-in
mehe
minha-ABS-mãe
barriga em 1sG-ABS-estar
COMP
$\begin{array}{lll}\text { u-màno } & \text { he-r-u } & \text { a'e } \\ \text { 3sG-morrer } & \text { meu-GEN-pai } & \text { ele }\end{array}$
"Quando eu estava ainda na barriga da minha mãe, ele, meu pai, morreu."
(71) * re- $\varnothing$-apyk mehe
2sG-ABS-sentar COMP
“... quando você se senta."

Evidência de que o Caso do sujeito do verbo intransitivo realmente equivale ao acusativo / absolutivo, nas sentenças em (b) acima, advém das construções antipassivas. Essas construções se caracterizam pelas seguintes propriedades gramaticais: 
(72) Propriedades de construçôes antipassivas

(a) o objeto é marcado com a posposição de Caso oblíquo -ehe;

(b) o argumento externo é tratado morfologicamente da mesma maneira que os sujeitos de intransitivos, uma vez que só pode ser codificado no verbo por meio dos clíticos acusativos;

(c) o afixo antipassivo -puru deve figurar na raiz verbal.

As propriedades acima são particularmente evidentes pela alternância transitiva / antipassiva que se observa nos exemplos abaixo.

(73) a-?u pira

eu-comer peixe

"Eu como peixe"

(74) he- $\varnothing$-puru-?u-wer

eU-ABS-ANT-comer-DESID

"Eu quero comer peixe."

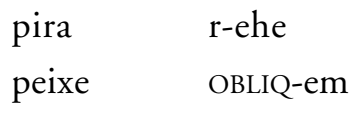

peixe OBLIQ-em

$\mathrm{Na}$ construção antipassiva em (74), a codificação do sujeito de primeira pessoa dá-se necessariamente por meio do clítico acusativo he=. Já na construção transitiva em (73), a codificação do sujeito de primeira pessoa realiza-se necessariamente por meio do prefixo nominativo $a$-. Note-se que a distribuição morfossintática dos marcadores de pessoa, mostrada acima serve de evidência adicional a favor da generalização proposta em (66). Em suma, concluímos que o prefixo nominativo só pode ocorrer em contextos de atribuição de Caso nominativo, enquanto o clítico acusativo tem sua ocorrência restrita em contexto de atribuição de Caso acusativo. Essa correlação é tão forte que, se o prefixo nominativo $a$ - figurar na construção antipassiva, o resultado é uma sentença agramatical, conforme ilustra a situação abaixo:
(75) *a-puru-?u-wer
pira
r-ehe
1SG-ANT-Comer-DESID
peixe
OBLIQ-em
"Eu desejo comer peixe"

Por conseguinte, a agramaticalidade acima claramente denota que somente clíticos acusativos podem codificar sujeito de construçôes antipassivas, fato que, por sua vez, fornece sustentação adicional para as seguintes hipóteses: 
(i) antipassivas são sintaticamente um subtipo de construção intransitiva;

(ii) o argumento externo é codificado no verbo da mesma maneira que sujeitos de intransitivos;

(iii) os marcadores de pessoas he ('eu') e $a$ - ('eu') possuem distribuição sintática distinta: o primeiro ocorre numa posição sintática de atribuição do Caso acusativo, enquanto o prefixo $a$-figura numa posição de atribuição de Caso nominativo;

(iv) os sujeitos de antipassivas recebem Caso acusativo / absolutivo, o qual é atribuído pelo núcleo $v$, e não pelo núcleo $\mathrm{T}$.

Evidência adicional a favor de que os marcadores de pessoas he ('eu') e $a$ ('eu') realmente têm sua distribuição condicionada ao Caso estrutural que os argumentos recebem no curso da derivação sintática surge das construções em que o sistema inverso emerge. Em tenetehára, assim como em outras línguas tupiguarani, a hierarquia de pessoa restringe a escolha dos marcadores de pessoa. Ademais, nessa hierarquia a primeira pessoa é sempre mais alta que a segunda; a segunda, por sua vez, é sempre mais alta que a terceira pessoa. O interessante é que os prefixos nominativos são acionados sempre que o sujeito estiver mais alto nesta hierarquia. O contrário também é verdadeiro, de sorte que, quando o objeto é mais alto que o sujeito na hierarquia de pessoa, os clíticos acusativos são usados, resultando, portanto, no que a literatura técnica convencionou chamar de sistema inverso. ${ }^{19}$ Comparem-se os exemplos abaixo.

$\mathrm{A}>\mathrm{O}$

(76a)

a-(a)ro-rəm awa

I-esperar-FUT homem

"Eu vou esperar pelo homem."

$\mathrm{O}>\mathrm{A}$

(76b) he.r-aro-rəm

awa

2SG-ACC-esperar-FUT homem

"O homem vai esperar por mim."

Contudo, quando o sujeito e objeto são realizados por meio de D/NPs plenos, o argumento mais alto na hierarquia será aquele que carregar os traços 
de foco e de especificidade. Esta hierarquia pode ser informalmente formulada da seguinte maneira: $1>2>3^{\text {focal }}>3^{\text {não-focal }}$. Os exemplos a seguir ilustram esses contextos sintáticos.

$$
\mathrm{A}>\mathrm{O}
$$

(77a) $w_{i}-e x a k$

Fábio $_{i}$

Márcia

3SG-ver

Fábio

Márcia

"Fábio viu Márcia."

$\mathrm{O}>\mathrm{A}$

$(77 \mathrm{~b})$
upaw Márcia ${ }_{\mathrm{i}} \quad$ Fábio $\quad \mathrm{h}_{\mathrm{i}}$-exak- $\varnothing$
todo Márcia Fábio 3sG-ver-DESLOC
"Toda a Márcia, Fábio viu (ela).”

Consequentemente, em função do fato de os clíticos acusativos poderem codificar o objeto de verbos transitivos, o sujeito de antipassivas e os sujeitos de intransitivos em sentenças encaixadas, uma conclusão natural é considerar que, nesses contextos, o núcleo $v$ sistematicamente atribui Caso acusativo. Tal proposta, por sua vez, me leva a admitir que, nos verbos inergativos, inacusativos e antipassivos, $v \mathrm{P}$ constitui uma fase forte, conforme indicam as estruturas sintáticas a seguir:

(78) Atribuição do Caso do sujeito de construções antipassivas

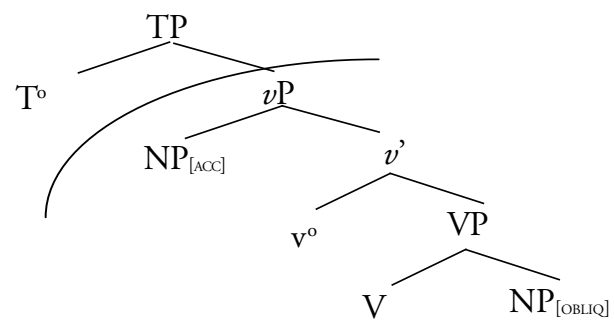


(79) Atribuição do Caso do sujeito de verbos inacusativos em sentenças encaixadas

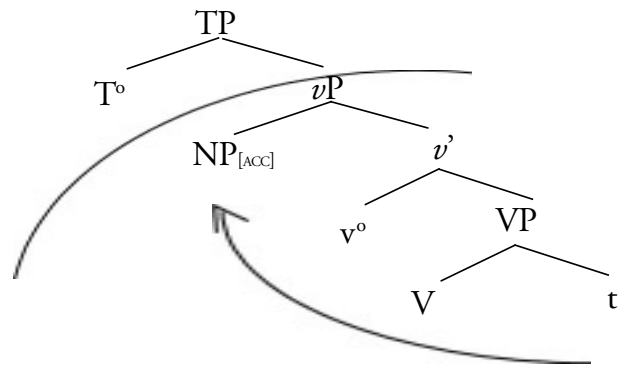

Aproposta acima estipula que o núcleo functional T não entra na derivação sintática com Caso a atribuir. Dessa maneira, o Caso estrutural do sujeito da antipassiva e do sujeito de verbo inacusativo é checado ainda na fase $v \mathrm{P}$, antes de o núcleo $\mathrm{T}$ ser concatenado na derivação.

Em suma, tomando por base os dados apresentados até aqui, tenho condiçôes de propor que o Caso do sujeito de verbos intransitivos (inergativos e inacusativos) não é uniformemente atribuído. A razão para isso tem a ver com o fato de que, em tenetehára, o Caso desses sujeitos pode ser checado pelo núcleo T ou pelo núcleo $v$. Evidentemente, a escolha de um ou outro núcleo depende do contexto sintático, ou seja, se a oração é raiz ou subordinada. Esse fato me leva ainda a concluir que o sistema de Caso em tenetehára exibe um padrão de ergatividade cindida, já que essa língua apresenta características de línguas acusativas e de línguas ergativas. Nesse sentido, concluo que o tenetehára permite uma variação paramétrica não prevista pelo OCP, já que o Caso estrutural do sujeito de verbos intransitivos pode ser o nominativo ou o acusativo, conforme a formulação abaixo.

\section{Sistema Cindido na atribuição de Caso a sujeitos intransitivos}

(80) Se $C 1_{\text {nominativo e }} \mathrm{C} 2_{\text {acusativo/absolutivo }}$ são ativos
(a) $V_{\text {transitivo }}$
( $\left.\mathrm{C} 1_{\text {nom }}\right)$
$\left(\mathrm{C} 2_{\mathrm{abs}}\right)$
(b) $V_{\text {intransitivo }}$
$\left(\mathrm{C} 1_{\text {nom }}\right)$
(c) $V_{\text {intrasintivo }}$
$\left(\mathrm{C} 2_{\mathrm{abs}}\right)$ 
A proposta acima traz, portanto, sustentação adicional a favor da hipótese de Levin e Massam (1986), Bobaljik (1993), Laka (1993, 2006), Woolford (2003), entre outros, segundo a qual a generalização de Burzio não é um princípio da gramática universal, mas uma propriedade muito peculiar das línguas nominativas. Vemos, assim, que línguas com ergatividade cindida, como o tenetehára e possivelmente outras línguas da família tupi-guarani, permitem um sistema híbrido de atribuição de Caso ao único argumento dos verbos intransitivos. Em suma, a língua tenetehára exibe as seguintes características sintáticas:

(i) sujeitos de verbos intransitivos podem receber Caso nominativo ou acusativo;

(ii) sujeitos de verbos transitivos antipassivizados recebem uniformemente Caso acusativo;

(iii) Generalização de Burzio é violada;

(iv) o objeto de verbos transitivos recebe uniformemente o Caso acusativo, o qual é atribuído pelo núcleo vo;

(v) o sujeito de verbos transitivos recebe uniformemente o Caso nominativo do núcleo $\mathrm{T}$ em orações raízes e subordinadas;

Tendo em conta as propriedades descritas acima, o sistema de Caso da língua tenetehára pode ser mais bem formalizado por meio do quadro a seguir:

\begin{tabular}{|l|c|c|c|}
\hline \multicolumn{4}{|c|}{ SISTEMA DE CASO TENETEHÁRA } \\
\hline Tipos de construção & $\begin{array}{c}\text { Sujeitos } \\
\text { intransitivos }\end{array}$ & $\begin{array}{c}\text { Objeto de } \\
\text { transitivos }\end{array}$ & $\begin{array}{l}\text { Sujeito de } \\
\text { transitivos }\end{array}$ \\
\hline Oração raiz & NOM & ACC & NOM \\
Construção antipassiva & - & OBLIQUE & ACC \\
Sistema inverso & - & ACC & NOM \\
Oração subordinada & ACC & ACC & NOM \\
\hline
\end{tabular}

\section{Considerações finais}

Tomando por base os dados das várias línguas ergativas investigadas neste artigo, fico em condições de concluir que, de fato, a ergatividade não é realmente um fenômeno homogêneo como se verifica em línguas nominativas, mas, ao 
contrário, apresenta particularidade de língua a língua. Tal conclusão me permite postular que há pelo menos três tipos de línguas ergativas. No primeiro tipo, observa-se que o núcleo $v$ não pode atribuir Caso acusativo ao objeto, já que este não é licenciado em orações finitas, pois o Caso deste argumento é dependente do núcleo T. Neste tipo de língua não há cisão, uma vez que o sujeito de intransitivos, de antipassivas e o objeto de transitivos receberão uniformemente Caso nominativo. Note que essas propriedades são condições necessárias para que uma língua seja considerada sintaticamente ergativa. Já no segundo tipo de ergatividade, o núcleo $v$ será capaz de atribuir Caso acusativo, como se verifica em warlpiri e em maxacali. Essas línguas não exibem as propriedades de línguas sintaticamente ergativas pelas seguintes razões:

(i) o objeto de verbos transitivos não recebe Caso do núcleo T;

(ii) o sujeito de verbos de ação pode receber Caso ergativo inerentemente na estrutura temática;

(iii) o sujeito de verbo intransitivo e sujeito de verbo antipassivado recebe Caso nominativo, tal como ocorre em warlpiri.

Já no terceiro tipo, exemplificado pela língua tenetehára, o Caso do sujeito do verbo intransitivo não é uniformemente atribuído, podendo equivaler a acusativo ou a nominativo. A escolha de um ou outro será sensível ao contexto sintático, de sorte que o acusativo será atribuído pelo núcleo $v$ em orações encaixadas, e o nominativo, pelo núcleo $\mathrm{T}$ em orações raízes. Outra diferença crucial é que o Caso do sujeito nas construções antipassivas não é atribuído pelo núcleo T, mas pelo núcleo $v$, situação que abre uma possibilidade paramétrica não prevista pela literatura linguística.

\section{Notas}

${ }^{1}$ Professor Adjunto IV da Faculdade de Letras da Universidade Federal de Minas Gerais. Bolsista de produtividade em pesquisa do CNPq - Nível 2. E-mail para contato:fbonfim@terra.com.br. Página na internet: www.letras.ufmg.br/fbonfim. Este estudo é parte de um projeto de pesquisa intitulado Ergatividade em Linguas Indigenas Brasileiras e suas consequências para a teoria de caso, o qual integra um projeto maior, apoiado pelo CNPq (Processo 302674/2009-8).

${ }^{2}$ No decorrer deste texto, referirei à categoria gramatical Caso com letra maiúscula para diferir de caso, substantivo comum. 
${ }^{3} \mathrm{O}$ filtro de Caso foi proposto originalmente por Chomsky e prevê que qualquer $\mathrm{D} / \mathrm{NP}$ foneticamente realizado precisa receber Caso abstrato.

${ }^{4}$ Bobaljik (2006, p. 53), por exemplo, considera que sistemas ergativos constituem um epifenômeno, em virtude de serem engatilhados por fatores diversos. Para o autor: "ergativity may be no more a single syntactic phenomenon than is, say, verb-initialness (...)."

${ }^{5}$ Legate (2006, p. 152) assume o seguinte: "Transitive $v$ also assigns inherent ergative case to the subject 'dog'. Subsequently, T undergoes $\varphi$-feature agreement with the highest $D P$, here the thematic subject 'dog', and the EPP feature of T attracts this DP to the specifier of TP. Nominative case is not licensed on 'dog', as 'dog' already bears inherent ergative case. (...) In an intransitive clause, neither structural accusative case nor inherent ergative case is assigned. The single argument (be it a thematic object or the thematic subject) undergoes $\varphi$-feature agreement with $T$, has its nominative case licensed by $T$, and is attracted to the specifier of TP to satisfy the EPP feature of T."

${ }^{6}$ Essa restrição foi inicialmente proposta por Chomsky (2004) e estipula que somente a borda de uma fase (vP ou CP) é acessível a operações fora desse domínio.

${ }^{7}$ Esta proposta está em consonância com o que Woolford (2007, p. 1595) argumenta: "The descriptive label 'absolutive' came into common use to gloss the morphologically unmarked Case on intransitive subjects and transitive objects in ergative languages in the mid 1970s, e.g. Anderson 1976, Chung 1978, Dixon 1980; in earlier work, it was standard to identify this Case as nominative, e.g. Hockett 1958, Hohepa 1969, Dixon 1972 (Joseph Foster, personal communication). (...) Although 'absolutive' might be useful as a descriptively neutral label to use as a placeholder until the identify of the Case or Cases involved can be determined, there is no evidence that 'absolutive' is an actual Case (GODDARD, 1982; LEGATE, 2006).

${ }^{8}$ Aldridge (2008), acompanhando proposta inicial de Legate (2002, 2008), assume o seguinte: "Specifically, Legate proposes that there is no 'absolutive' case assigned in the syntax. Rather, structural cases in ergative languages are assigned in the same way that they are in accusative languages: nominative by finite $T$ and accusative by transitive $v$. The surface manifestation of the ergative absolutive case pattern is realized post-syntactically in the morphological component, where the two structural cases are spelled out as a single default form."

${ }^{9}$ Nessa linha de investigação, Aldridge (2008) postula o seguinte: “(...) syntactic ergativity can be defined in terms of the dislocative and interpretive properties of absolutive. On this view, absolutives do not need to be analyzed as either subjects or objects. Rather, their mixture of subject and object properties can be reduced to their position in the structure, an analysis that is made possible by the c-command approach to case assignment. (...)

${ }^{10}$ Para detalhes mais refinados sobre o maxacali, remeto o leitor à tese de doutorado de Campos (2008) e aos seus artigos mais recentes $(2007,2008)$. 
${ }^{11}$ Aldridge (2008, p. 921), por exemplo, assume o seguinte: "Morphological ergativity is defined by the uniform assignment of inherent Case to the subject by transitive v, as proposed by Legate (2002, 2008). The types of morphological ergativity are distinguished in terms of whether transitive $v$ can assign structural Case."

${ }^{12}$ Os dados do ka'apor arrolados nesta pesquisa foram obtidos a partir do trabalho a campo que realizei nas aldeias ka'apor e a partir dos dados que estão disponíveis nas dissertações de mestrado de Caldas (2001) e Silva (2001).

${ }^{13}$ Dixon (1994, p. 62) postula que "in many ergative languages, the absolutive NP must obligatorily be included in each sentence, but an ergative NP may be omitted (...)". De acordo com essa proposta, podemos assumir o seguinte:

(i) o absolutivo é Caso não marcado;

(ii) o Caso ergativo é sempre o marcado.

${ }^{14}$ Saksena (1980, p. 821) assume que agentes afetados sofrem uma mudança de estado física ou psicológica. Em outras palavras, "these agents have some of the properties that one typically expects of patients. These agents are not only doers (performers of their activities) but also doees (recipients of these same activities)."

${ }^{15}$ Dixon (1994, p. 71) propõe que o sistema S-fluido emprega uma marcação de base semântica somente para verbos inergativos, de tal forma que um sujeito inergativo pode ser marcado como $S_{a}$, isto é, como o sujeito agente de verbos transitivos (A), ou como $\mathrm{S}_{\mathrm{o}}$, isto é, como o objeto transitivo $(\mathrm{O})$, a depender da semântica de cada caso particular. ${ }^{16}$ Nesse sentido, Dixon (1994, p. 81) afirma que “(..) fluid-S characteristics have been reported for at least one language from South America - baniwa do içana (.....Arawak family)."

${ }^{17}$ Woolford (2006) formula esta correlação por meio da seguinte generalização:

(i) Complementary distribution of lexical and inherent Case Lexical Case may occur on themes/internal arguments, but not on external arguments or on (shifted) DP goal arguments. Inherent Case may occur on external arguments and on (shifted) DP goal arguments but not on themes/internal arguments

${ }^{18}$ Para mais detalhes sobre o sistema de Caso e concordância da língua tenetehára, remeto o leitor aos meus textos mais recentes (2003, 2006, 2007, 2009, 2010, 2012a, 2012b). ${ }^{19}$ No âmbito da literatura tupi, este fenômeno tem recebido vários rótulos descritivos, a saber: sentenças invertidas, conforme Bendor-Samuel (1972) e sistema inverso, conforme Payne (1994). Harrison (1986, p. 417), por exemplo, nota que "(...) this grammatical device is not a true promotion, in the sense where passive promotes a direct object to subject". 


\section{Referências}

ALVES, Flávia de Castro. O Timbira falado pelos Canela Apãniekrá: uma contribuição aos Estudos damorfossintaxe de uma língua Jê. 2004. 177f. Tese (Doutorado) - Instituto de Estudos da Linguagem, Universidade Estadual de Campinas, Campinas, 2004. ANDERSON, S. On the notion of subject in ergative languages. In: LI, C. (Org.). Subject and Topic. New York: Academic Press, 1976. p. 1-23.

ALDRIDGE, E. Ergativity and word order in Austronesian Languages. 2004. Tese (Doutorado) - 2004.

ALDRIDGE, E. Phase theory account of absolutive extraction in Tagalog In: MCGINNIS, Martha; RICHARD, Norvin (Ed.). Perspectives on Phases. MITPWL, n. 49, 2005.

ALDRIDGE, E. Generative approaches to ergativity. Language and Linguistics Compass. 2/5, p. 966-995, 2008.

BENDOR-SAMUEL, D. Hierarchical structures in Guajajára. Oklahoma: University of Oklahoma, Norman, 1972.

BITTNER, M.; HALE, K. The structural determination of case and agreement. Linguistic Inquiry, v. 27, p. 1-68, 1996.

BOBALJIK, J. D. Ergativity and ergative unergativies. In: PHILLIPS, C.; BOBALJIK, J. D. (Ed.). Papers on Case and agreement I. MITWPL, n. 19, Cambridge: MIT Press, 1993.

BOBALJIK, J. D.; BRANIGAN, P. Eccentric Agreement and Multiple Case Checking In: JOHNS, Alana; MASSAM, Diane; NDAYIRAGIJE, Juvenal. Ergativity. London: Springer, 2006.

BURZIO, L. Italian syntax: a government and binding approach. Dordrecht: Reidel, 1986.

CALDAS, Raimunda Benedita. Aspecto, modo de ação e modalidade na língua kảapor. 2001. 86p. Dissertação (Mestrado em Lingüística) - UFPA, Belém, 2001.

CAMPOS, Carlo Sandro de Oliveira. Ergatividade cindida em maxacali. In: DUARTE, F. B. Cisão de Caso, telicidade e posse em linguas indígenas brasileiras. Belo Horizonte: UFMG, Cadernos Viva Voz, 2007.

CAMPOS, Carlo Sandro de Oliveira. Morfofonêmica e morfossintaxe do maxacali. 143 f. Tese de Doutorado (em andamento). Faculdade de Letras. UFMG, Belo Horizonte, 2008a. 
CAMPOS, Carlo Sandro de Oliveira. Maxacali: língua ergativa tripartida? ENCONTRO DE LÍNGUAS E CULTURAS MACRO-JÊ, 6, 2008, Goiânia. Comunicação. Goiânia: Universidade Federal de Goiás, 2008b.

CHOMSKY, Noam. Minimalist inquiries: The framework. In: MIT Occasional Papers in Linguistics, 15. Cambridge, MA: MIT, 1998.

CHOMSKY, Noam. Derivation by phase. MIT Occasional Papers. Cambridge: MIT Press, 1999.

CHOMSKY, Noam. On phases. Cambridge: MIT, Ms., 2004.

CHUNG, S. Case marking \& grammatical relations in Polynesian. Austin, Texas: University of Texas Press, 1978.

CZEPLUCH, H. Case patterns in German: Some implications for the theory of abstract Case. In: McGill Working Papers in Linguistics, Special Issue on Comparative Germanic Syntax. Montreal, Canada: Department of Linguistics, McGill University, 1988. p. 79-122.

DIXON, R. M. W. The Dyirbal language of North Queensland. Cambridge, MA: Cambridge University Press, Cambridge, MA, 1972.

DIXON, R. Ergativity. Language, v. 55, p. 59-138, 1979.

DIXON, R. M. W. The Languages of Australia. Cambridge, MA: Cambridge University Press, 1980.

DIXON, R. Ergativity. Cambridge: Cambridge University Press, 1994.

DUARTE, Fábio Bonfim. Ordem de constituintes e movimento em tembé: minimalismo e anti-simetria. 2003. 198f. Tese (Doutorado em Linguística) - Faculdade de Letras, Universidade Federal de Minas Gerais, Belo Horizonte 2003.

DUARTE, Fábio Bonfim. Codificação de argumentos e ergatividade (cindida) em tenetehará. In: Liames 4, Campinas: Unicamp, p. 113-145, 2006.

DUARTE, Fábio Bonfim. Estudos de morfossintaxe tenetehára. Belo Horizonte: UFMG, Editora da Fale/UFMG, 2007. 220 p.

DUARTE, Fábio Bonfim. Fonte de valoração do Caso ergativo e do Caso absolutivo em línguas indígenas brasileiras. Linguistica, v. 4, p. 111-135, 2009.

DUARTE, Fábio Bonfim; BARCELOS-SILVA, Isadora Maria. Natureza do caso ergativo e dativo em línguas Jê e suas consequências para a Teoria de Caso. Revista de Estudos da Linguagem, v. 18, p. 101-139, 2010.

DUARTE, Fábio Bonfim. Tenetehára: a predicate fronting language. Canadian Journal of Linguistics, v. 57, n.3, 2012a. 
DUARTE, Fábio Bonfim. Unaccusatives that do assign accusative. Artigo apresentado no Linguistic Association of Great Britain, setembro de 2012b, ms.

DUARTE, Fábio Bonfim. The S-split system and the source of the absolutive Case in tenetehára. Belo Horizonte: UFMG, 2012. (Mimeo)

FERREIRA, Marília. Aspectos das classes de palavras em Parkatêjê: uma abordagem tipológico-funcional. In: CABRAL, Ana Suelly Arruda Câmara; RODRIGUES, Aryon Dall'igna (Org.). Estudos sobre línguas indigenas. Belém: UFPA, 2001. p. 147-166.

GODDARD, C. Case systems and case marking in Australian languages: a new interpretation. Australian Journal of Linguistics, v. 2, p. 167-196, 1982.

HARRISON, Carl. Verb prominence, verb initialness, ergativity, and typological disharmony in Guajajára. In: DERBYSHIRE, D. C.; PULLUM, G. K. (Org.). Handbook of Amazonian Languages, v. 1, New York, Berlin: Mouton de Gruyter, 1986. p. 407-439. HOCKETT, C. F. A course in modern linguistics. Macmillan, New York, 1958.

HOHEPA, P. The accusative to ergative drift in Polynesian languages. Journal of the Polynesian Society, v. 78, p. 295-329, 1969.

JÓNSSON, J. G. Not so quirky: On subject Case in Icelandic. In: BRANDNER, Ellen; ZINSMEISTER, Heike (Org.). New Perspectives on Case Theory. Stanford, California: CSLI Publications, 2003. p.127-163.

LAKA, Itziar. Unergatives that assign ergative, unaccusatives that assign accusative. In: PHILLIPS, C.; BOBALJIK, J. D. (Ed.). Papers on Case and agreement I. MITWPL, n. 19, MIT, 1993.

LAKA, Itziar. Thetablind Case: Burzio's Generalization and its image in the mirror. In: REULAND; Eric J (Ed.). Arguments and Case. Explaining Burzio's Generalization. Amsterdam / Philadelphia: John Benjamins Publishing Company, 2000. p.103-129. 29 citas. ISBN 902722755.

LAKA, Itziar. On the nature of case in Basque: structural or inherent? In: BROEKHUIS. Hans; CORVER, Norbert, KOSTER, Jan, HUYBREGTS, Riny; KLEINHENZ, Ursula (Ed.). Organizing Grammar: Linguistic Studies in Honor of Henk van Riemsdijk. Berlin / New York: Mouton de Gruyter, 2006. p. 374-382. 14 citas. ISBN 3-11-018850-3

LEGATE, J. A. Warlpiri: Theoretical Implications. 2002. Tese (Doutorado) - 2002.

LEGATE, J. A. Split Absolutive. In: JOHNS, Alana; MASSAM, Diane; NDAYIRAGIJE, Juvenal. Ergativity. London: Springer, 2006.

LEGATE, J. A. Morphological and abstract case. Linguistic Inquiry, v. 39, p. 55101, 2008. 
LEVIN, B. On the Nature of Ergativity. Doctoral dissertation, MIT, 1983.

LEVIN, Beth. The Basque verbal inventory and configurationality. In: MARÁCZ, László; MUYSKEN, Pieter (Ed.). Configurationality: The typology of asymmetries. Dordrecht: Foris, 1989. p. 39-62.

LEVIN, L.; SIMPSON, Jane. Quirky Case and lexical representations of Icelandic verbs. In: Papers from the Seventeenth Regional Meeting. Chicago Linguistics Society, University of Chicago, Chicago, 1981. p. 185-196.

LEVIN, B.; MASSAM, D. Surface Ergativity: Case / theta relations reexamined. Proceedings of NELS 15, p. 286-301, 1986.

PAYNE, Doris. The Tupí-Guaraní inverse. In: FOX, Barbara; HOPPER, Paul (Org.). Voice: Form and function. Amsterdam: John Benjamins, 1994. p. 313-340.

SAKSENA, A. The affected agent. Language, n. 56. v.4, p.812-826, 1980.

SHIBATANI, M. Grammatical relations and surface Cases. Language, v. 53, p. 789-807, 1977.

SILVA, Tabita Fernandes. Classes verbais e algumas questôes pragmáticas em kảapor. 2001. 79f. Dissertação (Mestrado em Lingüística) - UFPA, Belém, 2001.

URA, H. Case. In: BALTIN, Mark.; COLLINS, Chris (Ed.). The Handbook of Contemporary Syntactic Theory. Oxford: Blackwell, 2001. p. 334-373.

WOOLFORD, Ellen. Case Locality: pure domains and object shift. Lingua, v. 117, p. 1591-1616, 2007.

WOOLFORD, Ellen. Burzio's Generalization, Markedness, and Locality Constraints on Nominative Objects. In: BRANDNER, E.; ZINSMEISTER, H. (Ed.). New Perspectives on Case Theory. Stanford, CA: CSLI, 2003, 2001. p. 301-329.

WOOLFORD, Ellen. Lexical Case, Inherent Case, and Argument Structure. Linguistic Inquiry. v. 37, n. 1,Cambridge: MIT Press, Winter, 2006. 